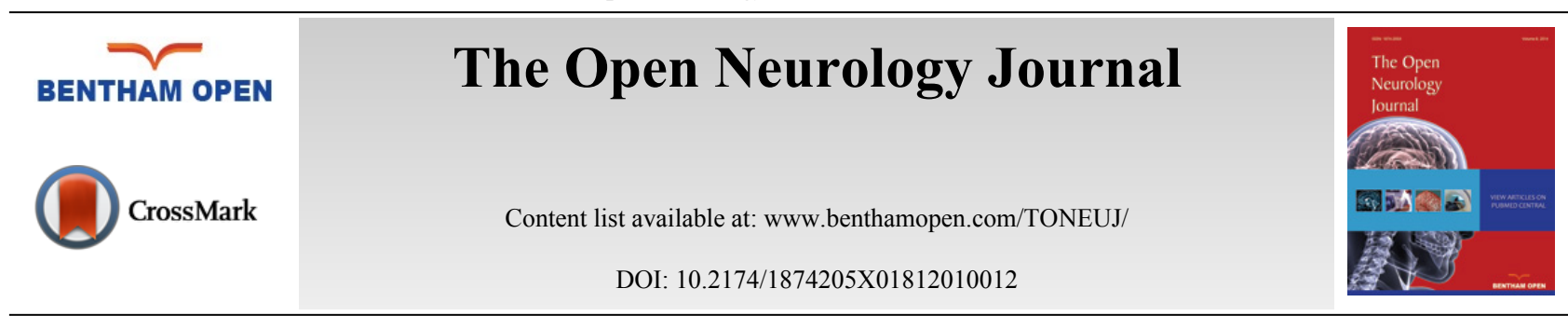

RESEARCH ARTICLE

\title{
A High-fat and High-Cholesterol Diet Potentiates Oxidative Damage in Hippocampus of Mice Lacking Apolipoprotein E
}

\author{
Mary Guaraldi and Thomas B. Shea* \\ Laboratory for Neuroscience, Department of Biological Sciences, University of Massachusetts Lowell, Lowell, MA \\ 01854, USA
}

Received: November 23, 2017

Revised: January 16, 2018

Accepted: January 20, 2018

\begin{abstract}
:
Objective:

We examined genetic and dietary challenge on hippocampal oxidative damage. Mice expressing (ApoE $+/+)$ or lacking apolipoprotein E (ApoE-/-) were maintained on a standard diet or a high fat /high cholesterol (challenge) diet for 11-31 weeks. Similar levels of oxidative species were observed for ApoE $+/+$ and -/- mice maintained on the basal diet.
\end{abstract}

\section{Method:}

However, treatment of ApoE-/- homogenates with hydrogen peroxide and iron increased oxidative species by $>100 \%$, indicating an equivalent amount of potential oxidative species in latent form. We observed a time- and region-specific induction of oxidative damage in the hippocampi of ApoE-/- but not +/+ mice while maintained on the challenge diet. Notably, however, additional significant latent oxidative products were detected during this time. After 31 weeks of dietary challenge, by which time hippocampal oxidative species had doubled, there was an additional $50 \%$ in the latent form.

\section{Conclusion:}

This highlights the degree to which ApoE deficiency places hippocampal tissue at risk for oxidative damage. Even a modest dietary deficiency may be sufficient to provoke oxidative damage to hippocampal tissue. These results highlight the combinatorial impact of genetic and dietary deficiencies on oxidative damage to hippocampal tissue.

Keywords: Oxidative damage, Latent oxidative damage, ApoE, Hippocampus.

\section{INTRODUCTION}

In addition to their well-known deleterious impact on cardiovascular physiology [1], diets high in saturated fat have been implicated in contributing to cognitive decline and neuronal degeneration observed with aging and with diseases such as Alzheimer's Disease (AD) [2 - 8].

Cholesterol and its metabolism may also play a role in the pathogenesis of AD. The incidence of AD is higher in countries with high-fat, high-cholesterol diets [9]. Cholesterol-lowering drugs may reduce the manifestation of AD in persons at risk [10]. High-fat diets can lead to increases in free radical formation [11] and oxidative stress is a major contributing factor to $\mathrm{AD}[12,13]$. Endogenous antioxidants such as glutathione help to prevent oxidative damage to tissues [14]. Dietary supplementation with folic acid, vitamin E, and other antioxidants has been shown to slowdown the progress of oxidative stress in brain tissue with subsequent reduction in cognitive deficits in mouse models [11, 14].

Apolipoprotein E (ApoE) is involved in lipid delivery and metabolism and is important for growth and repair of the

\footnotetext{
* Address correspondence to this author at the Laboratory for Neuroscience, Department of Biological Sciences, University of Massachusetts Lowell, Lowell, MA 01854, USA; Tel 978-934-2881; Fax: 978-934-3044; E-mail: thomas_shea@uml.edu
} 
nervous system. ApoE synthesis increases after neuronal injury and in $\mathrm{AD}[2,14,15]$ and may influence the degree of oxidative stress-induced damage in the frontal cortex of AD patients [16]. The E4 allele of ApoE has been implicated as a genetic risk for AD [17]. Transgenic mice lacking murine ApoE (ApoE-/- mice) demonstrated increased susceptibility to oxidative damage than their wild-type counterparts, which can be accompanied by neurodegenerative alterations and cognitive deficiencies, due at least in part to impaired antioxidant activity [2, $16-20]$. These mice therefore, represent a useful model for genetic predisposition to oxidative damage.

Herein, we examined the influence of a diet high in saturated fat and cholesterol on oxidative damage in hippocampal tissue of ApoE+/+ mice and ApoE-/- mice. We focused on the hippocampus due to its central and critical role in memory and since it displays some of the earliest impacts on $\mathrm{AD}[21,22]$.

\section{MATERIALS and METHODS}

\subsection{Mice and Treatments}

C57BL/6 mice homozygously expressing (ApoE+/+; Taconic Farms, Germantown, NY; $\mathrm{n}=12$ ) or lacking apolipoprotein E (ApoE-/-; bred in-house from stock originating from Jackson Labs, Bar Harbor, ME; n = 39) were maintained from weaning on a standard ("Basal”) diet (catalog \#5755, Test Diets, Richmond, IN) consisting of $21 \%$ vitamin-free casein, 15\% sucrose, 43.65\% Dextrin, 5\% corn oil, 5\% lard, 3\% non-nutritive fiber, RP vitamin and mineral mixtures, DL-methionine and choline chloride. This diet provided $19 \%$ protein, 10\% fat, $4.3 \%$ crude fiber, $60.6 \%$ carbohydrate and $4.08 \mathrm{kcal} / \mathrm{g}$ gross energy. The mice were then maintained for up to 31 weeks on a "high fat $/ \mathrm{high}$ cholesterol ("Challenge") diet (catalog \#21551; Test Diets) consisting of 31.6\% sucrose, $21 \%$ milk fat, $19.5 \%$ casein, $10 \%$ maltodextrin, RP vitamin and mineral mixtures, DL methionine, choline chloride, and $0.15 \%$ cholesterol (with ethoxyquin as a preservative). This diet provided $16.8 \%$ protein, $20.3 \%$ fat, $6.5 \%$ fiber, $48.8 \%$ carbohydrate, $2056 \mathrm{ppm}$ cholesterol and $4.52 \mathrm{kcal} / \mathrm{g}$ gross energy.

\subsection{Tissue preparation}

The mice were euthanatized by $\mathrm{CO}_{2}$ asphyxiation followed by decapitation in accord with Institutional Care and Use Committee approval. Brains were rapidly removed and stored at $-80^{\circ} \mathrm{C}$ until assayed. Hippocampi were weighed and homogenized with 9 volumes of ice-cold double-distilled $\mathrm{H}_{2} \mathrm{O}$ containing $0.4 \%$ butylated hydroxytoluene to inhibit auto-oxidation. Homogenates ( $50 \mu \mathrm{g}$ total protein) in $5 \mathrm{mM}$ HEPES containing $1 \mu \mathrm{M}$ copper sulfate were sonicated on ice $(2 \mathrm{x} 3 \mathrm{sec})$ then incubated for $60 \mathrm{~min}$ at $37^{\circ} \mathrm{C}$. Additional samples also received $0.1 \mathrm{mM}$ iron sulfate (JT Baker, Phillipsburg, NJ) and $0.1 \mathrm{mM}$ hydrogen peroxide (EMD Chemicals, Gibbstown, NJ) to maximize direct production of oxidation products [23].

\subsection{Measurement of oxidation products}

Thiobarbituric acid reactive substances (TBARS) were quantified as described [25] with minor modifications as follows: $1 \mathrm{ml}$ of $15 \%$ trichloroacetic acid containing $0.375 \%$ TBA and $0.25 \mathrm{~N} \mathrm{HCl}$ was added to the incubation mixture. Samples were vortexed, incubated at $90^{\circ} \mathrm{C}$ for $30 \mathrm{~min}$, placed on ice for $4 \mathrm{~min}$, followed by the addition of $4 \mathrm{~mL}$ butanol; pyridine (15:1). Samples were vigorously shaken and then centrifuged $\left(1500 \mathrm{xg}, 10 \mathrm{~min}\right.$ at $\left.4^{\circ} \mathrm{C}\right)$. The supernatant was decanted and assayed in a Shimadzu model 1501 spectrofluorophotometer (Shimadzu Scientific Instruments, Columbia, MD) with excitation and emission wavelengths at $520 \mathrm{~nm}$ and $553 \mathrm{~nm}$, respectively. The assay was repeated $3-4$ times for each experimental group and $\mu \mathrm{M}$ TBARS/mg total protein was determined by comparison to a standard curve of 1,1,3,3-tetramethoxypropane in $0.1 \mathrm{~N} \mathrm{HCl}$.

Values are presented as mean \pm standard error of the mean (SEM) for 6-12 mice per group. Statistical analyses were carried out for all conditions via ANOVA with post-hoc comparisions via Fisher's LSD and 2-tailed Student's $t$ tests. Reagents were obtained from Sigma-Aldrich (St Louis, MO) unless otherwise specified.

\section{RESULTS}

ApoE $+/+$ and -/- mice displayed identical levels of oxidative species in hippocampi when maintained on a standard diet. We converted all latent oxidative products to TBARS by the treatment of hippocampal homogenates with the prooxidants hydrogen peroxide plus iron. The conversion of latent oxidative species to TBARs revealed significant latent oxidative species in hippocampi of ApoE-/- mice maintained on a standard diet. By contrast, no latent products were detected in hippocampi of ApoE+/+ mice (Fig. 1). 


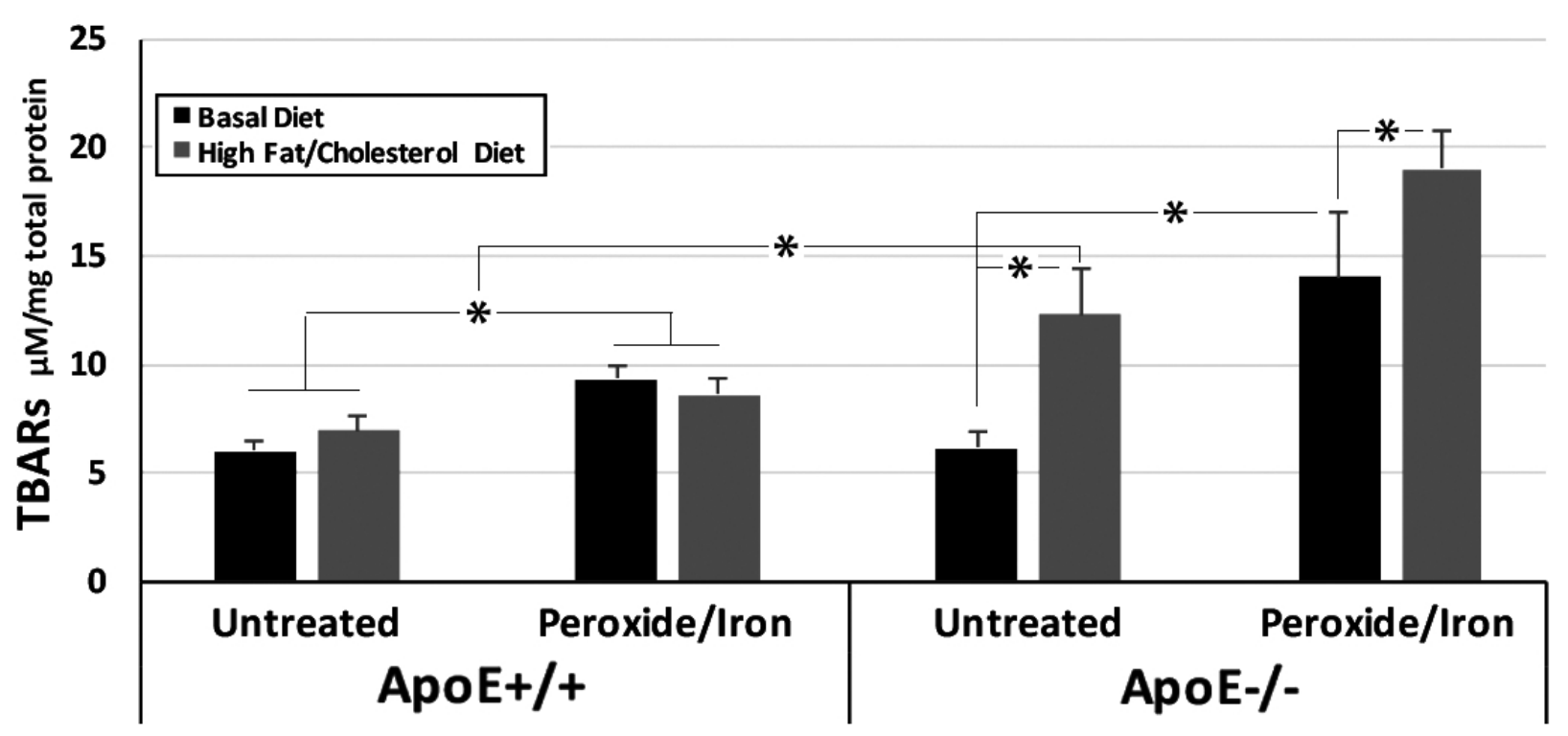

Fig. (1). Impact of the Challenge diet on oxidative species in hippocampi of mice expressing or lacking ApoE.

Maintenance on the Challenge diet for 31 weeks induced an approximately 50\% increase in TBARS in hippocampal homogenates from ApoE $+/+$ mice. An identical increase in TBARs was observed following the treatment of these homogenates with peroxide and iron, indicating that no additional latent oxidative products accumulated within ApoE $+/+$ hippocampi in response to this dietary challenge.

A $200 \%$ increase in oxidative species was observed in hippocampi of ApoE-/- mice following maintenance on the Challenge diet for 31 weeks. Treatment of these homogenates with peroxide and iron induced a further $48 \%$ increase in TBARs, indicating the presence of significant latent oxidative products. As in prior studies on dietary deficiency [24], maintenance of ApoE-/- mice on the challenge diet impaired Y maze navigation by $10 \%(55 \pm 3 \%$ at baseline; $49 \pm 6 \%$ after 31 weeks on the Challenge diet), consistent with a deleterious impact on hippocampal function.

Values represent $\mu \mathrm{M}$ TBARs / mg total protein (mean \pm standard error of the mean) in hippocampal homogenates from mice on the Basal diet or after 31 weeks on the Challenge diet, prior to and following treatment with peroxide and iron ( $\mathrm{n}=6 \mathrm{ApoE}+/+$ mice for each time point; $\mathrm{n}=9 \mathrm{ApoE}-/-$ mice for Basal and 12 for High fat/high cholesterol diets). Overall values among group were statistically different $(p<0.001$; ANOVA) $* p<0.05$ in post-hoc comparisons via $t$ test.

We monitored the time course of the increase in TBARS in ApoE-/- hippocampal homogenates. TBARs progressively increased over 21 weeks of maintenance on the high fat/high cholesterol diet, with no further increase by 31 weeks (Fig. 2). Treatment with peroxide and iron significantly increased TBARs at all times, indicating the presence of significant levels of latent oxidative products. A progressive significant increase in these latent oxidative products was observed over 31 weeks (Fig. 2).

The upper graph presents $\mu \mathrm{M}$ TBARs / mg total protein (mean \pm standard error of the mean) in hippocampal homogenates from ApoE-/- mice maintained for 0-31 weeks on the Challenge diet, prior to and following treatment with peroxide and iron ( $\mathrm{n}=9$ for 0,11 and 21 weeks and 12 for 31 weeks High fat/high cholesterol diets)). Overall values among group were statistically different $(p<0.01$; ANOVA) $* p<0.05$ in post-hoc comparisons via $t$ test.

The lower graph presents values for all times and conditions relative to time 0 (i.e., basal diet) without treatment with peroxide and iron, where this basal value is defined as 1 .

\section{DISCUSSION}

ApoE-/- mice are in general more vulnerable to oxidative stress, excitotoxic injury and ischemia [25 - 27], due, at least in part, to their inherently impaired antioxidant mechanisms [17 - 21,28]. Oxidative damage in hippocampus is consistent with our previous demonstration of cognitive decline following maintenance of ApoE-/- mice on a diet that fostered oxidative damage to overall brain tissue, and alleviation of cognitive decline by supplementation with antioxidants [15]. In prior studies, we examined the impact of dietary challenge on cortical tissue of ApoE-/- mice [20, 21]. Herein, we focused on hippocampal tissue since hippocampal function is critical in memory consolidation and 
displays some of the earliest signs of degeneration in $\operatorname{AD}[22,23,29]$. An increase in oxidative species was to be anticipated $[15,26,30]$ but what is particularly novel is the observation of a tremendous "reserve" of potential oxidative damage in the form of latent oxidative products. Even a modest dietary deficiency may therefore, be sufficient to provoke oxidative damage to hippocampal tissue.
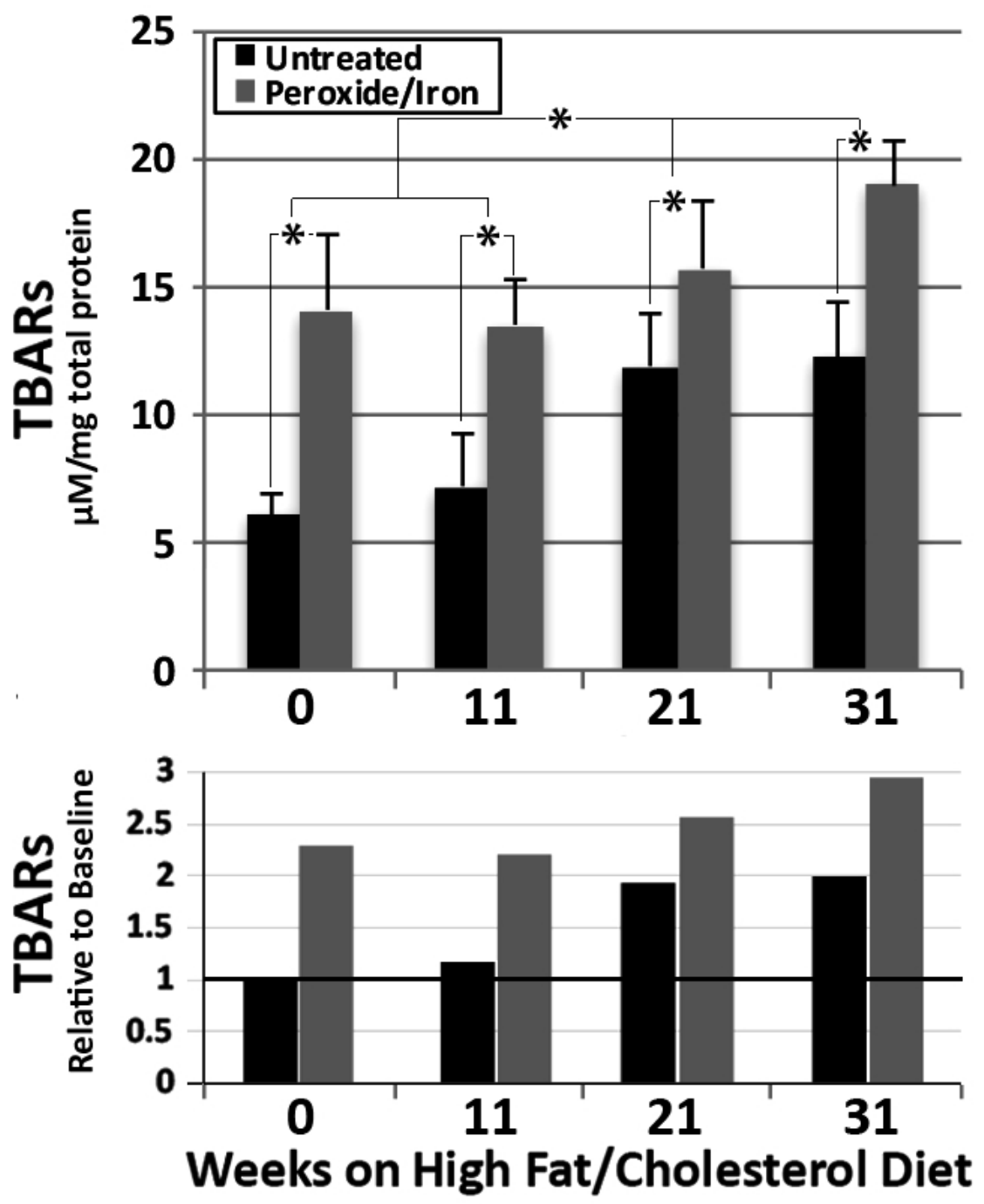

Fig. (2). Progressive increase in oxidative species following maintenance of ApoE-/- mice on the Challenge diet.

It has been difficult to demonstrate unequivocal impact of diet on dementia $[8,30]$. Notably, unlike pharmacological studies, nutritional studies are inherently compromised due to the difficulty of recruiting sufficient numbers of individuals who have inadequate baseline nutrition, such that a cohort with defined initiation of supplementation can be compared to a placebo cohort not receiving supplementation. While nutritional intervention may more likely to be effective for individuals who had prior chronic insufficiency; that very population is more likely to already have latent damage that may preclude any beneficial effect. However, animal studies, which are readily controlled, support these hypotheses. For example, maintenance on a high-fat diet induced a decline in synaptic transmission, synapsin, learning and memory, brain-derived neurotrophic factor, cognitive performance and increased brain lesions and cognitive problems in rodent model [11, 29, 31 - 35]. These deleterious impacts can manifest during juvenile years [36], and in some instances, as a consequence of maternal consumption [31].

These findings add to a growing body of evidence that key dietary deficiencies can contribute to the onset of AD in some cases, by exacerbating otherwise latent genetic risks including the increased propensity for oxidative damage inherent in ApoE deficiency [30]. 


\section{ETHICS APPROVAL AND CONSENT TO PARTICIPATE}

All procedures were approved by our Institutional Animal Care and Use Committee.

\section{HUMAN AND ANIMAL RIGHTS}

All procedures were approved in accordance with the PHS Policy on Humane Care and Use of Laboratory Animals (http://grants2.nih.gov/grants/olaw/references/PHSPolicyLabAnimals.pdf).

\section{CONSENT FOR PUBLICATION}

Not applicable.

\section{CONFLICT OF INTEREST}

The authors declare no conflict of interest, financial or otherwise.

\section{ACKNOWLEDGEMENTS}

This research was supported by the Alzheimer's Association.

\section{REFERENCES}

[1] Chen Y, Wen S, Jiang M, et al. Atherosclerotic dyslipidemia revealed by plasma lipidomics on ApoE-/- mice fed a high-fat diet. Atherosclerosis 2017; 262: 78-86.

[http://dx.doi.org/10.1016/j.atherosclerosis.2017.05.010] [PMID: 28527370]

[2] Arendt T, Schindler C, Brückner MK, et al. Plastic neuronal remodeling is impaired in patients with Alzheimer's disease carrying apolipoprotein epsilon 4 allele. J Neurosci 1997; 17(2): 516-29.

[PMID: 8987775]

[3] Francis H, Stevenson R. The longer-term impacts of Western diet on human cognition and the brain. Appetite 2013; 63: 119-28. [http://dx.doi.org/10.1016/j.appet.2012.12.018] [PMID: 23291218]

[4] Hofman A, Ott A, Breteler MM, et al. Atherosclerosis, apolipoprotein E, and prevalence of dementia and Alzheimer's disease in the Rotterdam Study. Lancet 1997; 349(9046): 151-4. [http://dx.doi.org/10.1016/S0140-6736(96)09328-2] [PMID: 9111537]

[5] Molteni R, Barnard RJ, Ying Z, Roberts CK, Gómez-Pinilla F. A high-fat, refined sugar diet reduces hippocampal brain-derived neurotrophic factor, neuronal plasticity, and learning. Neuroscience 2002; 112(4): 803-14. [http://dx.doi.org/10.1016/S0306-4522(02)00123-9] [PMID: 12088740]

[6] Solfrizzi V, Capurso C, D'Introno A, et al. Dietary fatty acids, age-related cognitive decline, and mild cognitive impairment. J Nutr Health Aging 2008; 12(6): 382-6.

[http://dx.doi.org/10.1007/BF02982670] [PMID: 18548175]

[7] Solfrizzi V, Frisardi V, Capurso C, et al. Dietary fatty acids in dementia and predementia syndromes: Epidemiological evidence and possible underlying mechanisms. Ageing Res Rev 2010; 9(2): 184-99. [http://dx.doi.org/10.1016/j.arr.2009.07.005] [PMID: 19643207]

[8] Shea TB, Remington R. Positive argument for debate in J Neural Transmission: Alzheimer's disease: are we intervening too late? Yes, by years if not decades. J Neural Transm (Vienna) 2012; 119(12): 1529-32. [http://dx.doi.org/10.1007/s00702-012-0849-0] [PMID: 22782685]

[9] Refolo LM, Malester B, LaFrancois J, et al. Hypercholesterolemia accelerates the Alzheimer's amyloid pathology in a transgenic mouse model. Neurobiol Dis 2000; 7(4): 321-31.

[http://dx.doi.org/10.1006/nbdi.2000.0304] [PMID: 10964604]

[10] Jick H, Zornberg GL, Jick SS, Seshadri S, Drachman DA. Statins and the risk of dementia. Lancet 2000; 356(9242): 1627-31. [http://dx.doi.org/10.1016/S0140-6736(00)03155-X] [PMID: 11089820]

[11] Wu A, Ying Z, Gomez-Pinilla F. The interplay between oxidative stress and brain-derived neurotrophic factor modulates the outcome of a saturated fat diet on synaptic plasticity and cognition. Eur J Neurosci 2004; 19(7): 1699-707. [http://dx.doi.org/10.1111/j.1460-9568.2004.03246.x] [PMID: 15078544]

[12] Markesbery WR, Carney JM. Oxidative alterations in Alzheimer's disease. Brain Pathol 1999; 9(1): $133-46$. [http://dx.doi.org/10.1111/j.1750-3639.1999.tb00215.x] [PMID: 9989456]

[13] Zhu X, Raina AK, Lee HG, Casadesus G, Smith MA, Perry G. Oxidative stress signalling in Alzheimer's disease. Brain Res 2004; 1000(1-2): $32-9$. [http://dx.doi.org/10.1016/j.brainres.2004.01.012] [PMID: 15053949]

[14] De La Cruz JP, Quintero L, Villalobos MA, Sánchez de la Cuesta F. Lipid peroxidation and glutathione system in hyperlipemic rabbits: Influence of olive oil administration. Biochim Biophys Acta 2000; 1485(1): 36-44. 
[http://dx.doi.org/10.1016/S1388-1981(00)00027-5] [PMID: 10802247]

[15] Strittmatter W, Saunders A, Schmechel D, et al. High-avidity binding to B-amyloid and increased frequency of type 4 allele in late-onset familial Alzheimer disease. Proc Natl Acad Sci USA 1993; 90: 1977-81. [http://dx.doi.org/10.1073/pnas.90.5.1977] [PMID: 8446617]

[16] Veinbergs I, Mallory M, Sagara Y, Masliah E. Vitamin E supplementation prevents spatial learning deficits and dendritic alterations in aged apolipoprotein E-deficient mice. Eur J Neurosci 2000; 12(12): 4541-6. [PMID: 11122365]

[17] Raber J, Wong D, Buttini M, et al. Isoform-specific effects of human apolipoprotein E on brain function revealed in ApoE knockout mice: Increased susceptibility of females. Proc Natl Acad Sci USA 1998; 95(18): 10914-9. [http://dx.doi.org/10.1073/pnas.95.18.10914] [PMID: 9724804]

[18] Ramassamy C, Krzywkowski P, Averill D, et al. Impact of apoE deficiency on oxidative insults and antioxidant levels in the brain. Brain Res Mol Brain Res 2001; 86(1-2): 76-83.

[http://dx.doi.org/10.1016/S0169-328X(00)00268-0] [PMID: 11165374]

[19] Shea TB, Rogers E. Folate quenches oxidative damage in brains of apolipoprotein E-deficient mice: Augmentation by vitamin E. Brain Res Mol Brain Res 2002; 108(1-2): 1-6. [http://dx.doi.org/10.1016/S0169-328X(02)00412-6] [PMID: 12480173]

[20] Tchantchou F, Graves M, Ashline D, et al. Increased transcription and activity of glutathione synthase in response to deficiencies in folate, vitamin E, and apolipoprotein E. J Neurosci Res 2004; 75(4): 508-15. [http://dx.doi.org/10.1002/jnr.10867] [PMID: 14743434]

[21] de Flores R, La Joie R, Chételat G. Structural imaging of hippocampal subfields in healthy aging and Alzheimer's disease. Neuroscience 2015; 309: 29-50.

[http://dx.doi.org/10.1016/j.neuroscience.2015.08.033] [PMID: 26306871]

[22] Haam J, Yakel JL. Cholinergic modulation of the hippocampal region and memory function. J Neurochem 2017; 142(Suppl. 2): 111-21. [http://dx.doi.org/10.1111/jnc.14052] [PMID: 28791706]

[23] Buege J, Aust S. Microsomal and Lipid Peroxidation. Methods in Enzymology 1978; 52(52): 302-10.

[24] Rogers EJ, Milhalik S, Orthiz D, Shea TB. Apple juice prevents oxidative stress and impaired cognitive performance caused by genetic and dietary deficiencies in mice. J Nutr Health Aging 2004; 8(2): 92-7. [PMID: 14978604]

[25] Buttini M, Orth M, Bellosta S, et al. Expression of human apolipoprotein E3 or E4 in the brains of Apoe-/- mice: Isoform-specific effects on neurodegeneration. J Neurosci 1999; 19(12): 4867-80.

[PMID: 10366621]

[26] Kitagawa K, Matsumoto M, Hori M, Yanagihara T. Neuroprotective effect of apolipoprotein E against ischemia. Ann N Y Acad Sci 2002; 977: 468-75.

[http://dx.doi.org/10.1111/j.1749-6632.2002.tb04852.x] [PMID: 12480787]

[27] Lomnitski L, Oron L, Sklan D, Michaelson DM. Distinct alterations in phospholipid metabolism in brains of apolipoprotein E-deficient mice. J Neurosci Res 1999; 58(4): 586-92. [http://dx.doi.org/10.1002/(SICI)1097-4547(19991115)58:4<586::AID-JNR11>3.0.CO;2-7] [PMID: 10533050]

[28] Lee Y, Aono M, Laskowitz D, Warner DS, Pearlstein RD. Apolipoprotein E protects against oxidative stress in mixed neuronal-glial cell cultures by reducing glutamate toxicity. Neurochem Int 2004; 44(2): 107-18. [http://dx.doi.org/10.1016/S0197-0186(03)00112-8] [PMID: 12971913]

[29] Ledreux A, Wang X, Schultzberg M, Granholm AC, Freeman LR. Detrimental effects of a high fat/high cholesterol diet on memory and hippocampal markers in aged rats. Behav Brain Res 2016; 312: 294-304. [http://dx.doi.org/10.1016/j.bbr.2016.06.012] [PMID: 27343935]

[30] Shea TB, Rogers E, Remington R. 2012.

[31] Cordner ZA, Tamashiro KL. Effects of high-fat diet exposure on learning \& memory. Physiol Behav 2015; 152(Pt B): 363-71. [http://dx.doi.org/10.1016/j.physbeh.2015.06.008] [PMID: 26066731]

[32] Mainardi M, Spinelli M, Scala F, et al. Loss of Leptin-Induced Modulation of Hippocampal Synaptic Trasmission and Signal Transduction in High-Fat Diet-Fed Mice. Front Cell Neurosci 2017; 11: 225.

[http://dx.doi.org/10.3389/fncel.2017.00225] [PMID: 28804449]

[33] Kang DH, Heo RW, Yi CO, Kim H, Choi CH, Roh GS. High-fat diet-induced obesity exacerbates kainic acid-induced hippocampal cell death. BMC Neurosci 2015; 16: 72.

[http://dx.doi.org/10.1186/s12868-015-0202-2] [PMID: 26518260]

[34] Hoane MR, Swan AA, Heck SE. The effects of a high-fat sucrose diet on functional outcome following cortical contusion injury in the rat. Behav Brain Res 2011; 223(1): 119-24. [http://dx.doi.org/10.1016/j.bbr.2011.04.028] [PMID: 21549156]

[35] Wu A, Molteni R, Ying Z, Gomez-Pinilla F. A saturated-fat diet aggravates the outcome of traumatic brain injury on hippocampal plasticity and cognitive function by reducing brain-derived neurotrophic factor. Neuroscience 2003; 119(2): 365-75. 
[http://dx.doi.org/10.1016/S0306-4522(03)00154-4] [PMID: 12770552]

[36] Boitard C, Cavaroc A, Sauvant J, et al. Impairment of hippocampal-dependent memory induced by juvenile high-fat diet intake is associated with enhanced hippocampal inflammation in rats. Brain Behav Immun 2014; 40: 9-17. [http://dx.doi.org/10.1016/j.bbi.2014.03.005] [PMID: 24662056]

\section{(C) 2018 Guaraldi and Shea.}

This is an open access article distributed under the terms of the Creative Commons Attribution 4.0 International Public License (CC-BY 4.0), a copy of which is available at: https://creativecommons.org/licenses/by/4.0/legalcode. This license permits unrestricted use, distribution, and reproduction in any medium, provided the original author and source are credited. 